\title{
A ARTE COMO MANIFESTAÇÃO DA VIDA: A CONTRIBUIÇÃO DESENHO NO DESENVOLVIMENTO DA CRIANÇA
}

\author{
Catarina de Sene Lima e Silva Caldas, Carmen Lúcia Dias \\ Universidade do Oeste Paulista - UNOESTE, Mestrado em Educação, Presidente Prudente, SP. e-mail: \\ catacaldas@hotmail.com
}

\begin{abstract}
RESUMO
Este artigo apresenta uma sistematização teórica que tem por objetivo apresentar reflexões e contribuições sobre a arte, na manifestação da vida na criança e o desenho como expressão natural criativa. Por isso, propõe-se uma discussão acerca de questões pertinentes ao espaço ocupado pela arte no campo da Educação Infantil. A inclusão do desenho e os benefícios desta prática para o desenvolvimento infantil são discutidos a partir da contribuição de autores expoentes na área, sendo também abordados e recomendados no Referencial Curricular Nacional para a Educação Infantil, indicando ser efetiva à presença das linguagens artísticas na formação integral da criança. Refletindo sobre a importância das artes visuais para o desenvolvimento infantil, pretende-se analisar a importância das Artes Visuais como mediadora de experiências transformadoras, promovendo a construção integral do ser, aguçando a criatividade e imaginação, expandindo o seu conhecimento e a sua plena relação com o mundo.

Palavras-chave: Arte, Desenho, Educação Infantil, Referencial Curricular Nacional, Artes Visuais.
\end{abstract}

\section{THE ART AS MANIFESTATION OF THE LIFE: THE CONTRIBUTION DRAWING IN THE DEVELOPMENT OF THE CHILD}

\begin{abstract}
This article presents a theoretical systematization that has for objective to present reflections and contributions on the art, in the manifestation of the life in the child and the drawing as natural creative expression. Therefore, an argument concerning pertinent questions to the space taken by the art in the field of Childhood Education. The inclusion of the drawing and the benefits of this practical for the infantile development are argued from the contribution of illustrious representative authors in the area, being also boarded and recommended in the National Curricular Reference book for the Childhood Education, indicating to be it accomplishes the presence of the artistic languages in the integral formation of the child. Reflecting on the importance of the visual arts for the infantile development, it is intended to analyze the importance of the Visual Arts as mediating of transforming experiences, promoting the integral construction of the human being, sharpening the creativity and imagination, expanding its knowledge and its full relation with the world.
\end{abstract}

Keywords: Art, Drawing, Childhood Education, National Curricular Reference Book, Visual art. 


\section{INTRODUÇÃO}

A criação artística é um ato exclusivo da criança, ou seja, ela já traz isso em seu interior. É no fazer artístico e no contato com os objetos de arte que parte significativa do conhecimento em Artes Visuais acontece. Conforme o Referencial Curricular Nacional para a Educação Infantil (RCENEI):

O desenvolvimento
progressivo do desenho
implica mudanças
significativas que, no inicio,
dizem respeito á passagem
dos rabiscos iniciais da
garatuja para construções
cada vez mais ordenadas,
fazendo surgir os primeiros
símbolos. Imagem de sol,
figuras humanas, animais,
vegetação e carros, entre
outros, são freqüentes nos
desenhos das crianças,
reportando mais a
assimilações dentro da
linguagem do desenho do
que a objetos naturais. Essa
passagem é possível graças
às interações da criança
com o ato de desenhar e
com desenhos de outras
pessoas (BRASIL. Ministério
da Educação e Desporto,
1998, p.85).

Ainda o RCNEI aborda que no processo de aprendizagem em Artes Visuais, a criança traça um percurso de criação e construção individual que envolve escolhas experiências pessoais, aprendizagens, relação com a natureza, motivação interna e/ou externa; destaca também que o desenvolvimento do desenho tem uma grande importância no fazer artístico das crianças.

A arte é o maior meio criativo de exercitar a capacidade de criação do ser humano, pois a arte e sua ação cultural é o autêntico ato de conhecer e a educação cultural liberta como dizia Paulo Freire (1984, p.99).

[...] a educação ou a ação cultural para a libertação, em lugar de ser aquela alienante transferência de conhecimento, é o autêntico ato de conhecer, em que os educandos também educadores como consciências 'intencionadas' ao mundo, ou como corpos conscientes, se inserem com os educadores educandos também - na busca de novos conhecimentos, como consequência do ato de reconhecer o conhecimento existente.

Cabe à Educação estimular, pois muitas das aptidões artísticas ativam capacidades psíquicas das diversas formas, como o desenho, levando-o também a encontrar racionalidade dentro de seus sentimentos, enfim, tornar o desafio artístico que antes era mero entretenimento e, a 
partir do acesso às artes o indivíduo possa se encontrar como um ser único e especial.

Portanto, a partir de uma sistematização teórica, este artigo apresenta reflexões e contribuições sobre a arte, na manifestação da vida na criança e o desenho como expressão natural criativa. Para isto, propõe-se uma discussão acerca de questões pertinentes ao espaço ocupado pela arte no campo da Educação Infantil.

\section{A ARTE NA VIDA DA CRIANÇA}

A arte como um processo inicia desde cedo, muito antes do ingresso da criança na escola e evolui, fundamentalmente, através das interações que a criança mantém com o mundo físico e social e com o movimento das mãos em contato com o lápis e o papel.

Á medida que as crianças se desenvolvem, suas formas de expressão e sua arte também se transformam. As crianças desenham de formas previsíveis, passando por sucessivas fases.

De acordo com Lowenfeld (1978), quando as crianças começam a desenhar, é comum vermos diversos rabiscos, sejam eles na folha, no chão ou até mesmo na parede. Mas, cabe frisar que esses "rabiscos" são aquilo que os adultos vêem, e não de fato o que representam para as crianças; para elas são casas, pessoas, carros, etc.

Conforme as crianças crescem, aumentam suas habilidades de retratar no desenho coisas de seu cotidiano como figuras humanas, brinquedos e outras imagens e objetos que eles costumam ver no seu dia-adia. Toda criança desenha. Pode ser com lápis e papel ou com giz de cera na parede. Agir com um riscador sobre um suporte é algo que ela aprende por imitação ao ver os adultos escrevendo ou os irmãos desenhando.

A primeira relação da criança com o desenho acontece pelo movimento, onde o prazer de produzir um traço sobre o papel faz com que ela desenhe o que imagina. E um dos primeiros meios que a criança utiliza para manifestar-se é o movimento corporal: "Este período da vida é extremamente importante para o desenvolvimento de atitudes sobre o próprio eu para o estabelecimento da noção de que o mundo é um lugar empolgante e aprazível para se viver." (LOWENFELD, 1978, p.7)

Uma das principais funções do desenho no desenvolvimento infantil é a possibilidade que ele oferece de representação da realidade. Trazer os objetos vistos no mundo para o papel é uma forma de lidar com os elementos do dia-a-dia. Um exemplo disso são as crianças na escola, pois é muito comum vê-las imitarem a professora quando estão brincando. Muitas vezes essas imitações que elas fazem são baseadas nos detalhes, como a maneira de falar, andar e até mesmo brigar. No desenho, ocorre o 
mesmo, a diferença é que elas não usam o corpo, mas a visualidade e a motricidade.

De acordo com Lowenfeld (1978), o desenvolvimento criador se inicia logo que a criança começa a fazer seus primeiros rabiscos. Neste momento ela está de alguma maneira, tentando transmitir o que está imaginando através do desenho. O autor explica:

Se a criança em seu trabalho criador procura continuamente relacionar entre si todas as suas experiências, tais como pensar, sentir, perceber (ver, tocar), tudo isso deve também exercer um efeito de integração sobre a sua personalidade (LOWENFELD, 1978, p. 5)

Percebe-se que, para o autor, a criatividade da criança influencia na construção do seu "eu".

Segundo PIAGET (1973), psicólogo suíço e grande estudioso do desenvolvimento cognitivo infantil, introduziu os estágios de desenvolvimento: sensório-motor $\left(\begin{array}{lll}0 & \text { a } & 2\end{array}\right.$ anos); pré-operacional (2 a 7 anos); operatório-concreto (7 a 11 anos) e o operatório formal. Este desenvolvimento se inicia quando nascemos e termina na idade adulta, podendo ser comparado ao crescimento orgânico, que se caracteriza pela construção do crescimento e maturidade dos órgãos.
Também com esta idéia Freire coloca que o movimento corporal deve ser interpretado como um recurso pedagógico valioso no ensino fundamental, especialmente no primeiro segmento do ensino, pois "a mão escreve o que a mente pensa a respeito do mundo com o qual a criança interage" (FREIRE, 1992, p.81 apud DEVIDE, 2008). Pensando no ensino da arte para auxiliar em suas vivências, para ampliar seus aspectos cognitivos, procedimentais e atitudinais, assim proporcionando que o ambiente possa facilitar suas características e iniciando sua compreensão no meio e suas habilidades principalmente como um ser pensante, conduzindo-o a fase de desenvolvimento operatório-concreto (PIAGET, 1973).

Neste contexto, a arte/educação é um alicerce para desenvolver essa criatividade, pois a criança como um ser em constante aprendizagem, tem mais facilidade para o senso de observação e em diversas ocasiões, chama a atenção por suas particularidades. E ao utilizar sua liberdade de expressão e de investigação, com o auxílio de seus educadores, conclui-se que suas aprendizagens e seu desenvolvimento, paulatinamente, aumentam sua maneira de expressar e de visualizar o mundo.

As Artes expressam, comunicam e atribuem sentidos a sensações, sentimentos, pensamentos e realidade por vários meios, 
dentre deles, linhas formas, pontos, e ainda estão presentes no dia-a-dia da criança, de formas bem simples como rabiscar e desenhar no chão, na areia, em muros. Por isso é uma forma muito importante de expressão e comunicação humanas, o que justifica sua presença na educação infantil.

\section{A Educação Infantil}

O conceito de infância como um momento peculiar em nossas existências não é um sentimento natural ou inerente à espécie humana. A partir do século XVI, com a alteração na atitude de produção no Século $\mathrm{XVII}$, a criança passou a ser entendida como fator importante para a obtenção e conservação dos benefícios familiares, ou, se não fosse de família de posses, precisaria ser formada para o trabalho.

Fazendo parte do cotidiano da vida infantil, o RCNEI sugere que a prática das Artes Visuais seja abordada, visto que nesta faixa etária que vai dos dois até os quatro ou cinco, anos, a criança rabisca o chão, as paredes e os muros, desenha seu próprio corpo, pinta objetos, cria sua marca. Ele também propõe que:

[...] as Artes Visuais devem
ser concebidas como
linguagem que tem
estrutura e As Artes Visuais
expressam, comunicam e
atribuem sentido a
sensações, sentimentos,
pensamentos e realidade
por meio da organização de

linha, formas, pontos, tanto bidimensional como tridimensional, além de volume, espaço, cor e luz na pintura, no desenho, na escultura, na gravura, na arquitetura, nos brinquedos, bordados, entalhes etc. (BRASIL. Ministério da Educação e Desporto, 1998, p.85)

Esse saber artístico, característico de crianças pequenas, está repleto de concepções e idéias que revelam valores, emoções, sentimentos e significações sobre si e sobre o mundo que as rodeia. Mesmo sendo considerado um ato exclusivo, autônomo e espontâneo da criança, o processo de criação e construção artística pode ser significativamente enriquecido pela ação dirigida do professor. No processo do fazer artístico, também é importante que o professor promova a valorização e a interação das crianças com suas próprias criações artísticas, o que pode ser alcançado, por exemplo, a partir das exposições dos trabalhos realizados.

Fusari e Ferraz (1992) dizem que a educação através da Arte é, na verdade, um movimento educativo e cultural que busca a constituição de um ser completo, total, dentro dos moldes do pensamento idealista e democrático, valorizando no ser humano os aspectos intelectuais, morais e estéticos, procurando despertar sua consciência 
individual e harmonizada ao grupo social ao qual pertence.

\section{CONSIDERAÇÕES FINAIS}

Concluindo, ao produzir criativamente a criança aprende a expressar suas idéias, desenvolve o senso crítico e seu raciocínio, expõe sentimentos enfim desenvolver a criatividade acaba sendo o ponto mais importante do aprendizado da criança. O desenho é fundamental para o desenvolvimento pleno da criança e para a formação de esquemas mentais, pois estimula a criatividade e o desenvolvimento da criança. A expressão por sua vez é desenvolvida através da interpretação e da oralidade impressas no desenho.

Portanto, acreditamos que seja necessário sempre (re)pensar o ensino de Arte, visto que na atualidade, esta propõe uma ação educativa criadora, ativa e centrada no aluno para que este encontre um espaço para seu desenvolvimento pessoal e social por meio de vivência e posse do conhecimento artístico e estético.

\section{REFERÊNCIAS}

BRASIL. Ministério da Educação e do Desporto. Secretaria de Educação. Referencial curricular nacional para a educação infantil / Fundamental. Brasília: MEC/SEF, 1998.

DEVIDE, F. P. Educação física escolar no primeiro segmento do ensino fundamental: contribuições para um debate. 2008.
Disponível em: <file://C:/Users/Adminf/Downloads/96515703-1-PB.pdf>. Acesso: 28 mar. 2013.

FREIRE, P. Ação cultural para a liberdade. Rio de Janeiro: Paz e Terra, 1984.

FUSARI, M. F. R.; FERRAZ, M. H. C. T. Arte na

Educação Escolar. São Paulo: Cortez, 1992.

LOWENFELD, V. 0 que significa a arte para a criança? São Paulo: Mestre Jou, 1978.

PIAGET, J. Seis estudos em psicologia. São Paulo: Forense Universitária, 1973.

Recebido para publicação em 18/08/2014 Revisado em 19/09/2014 Aceito em 23/09/2014 